\title{
God and a 'Little Bit of Magic': Faith and Healing through the Lens of Cambodian Trauma Survivors
}

\author{
Zoe Wyatt $^{1 *}$, K. Morgan Welton ${ }^{2}$ \\ ${ }^{1}$ Hagar International, Mauritius, ${ }^{2}$ Facilitate Wellbeing, United States
}

Corresponding Author: ${ }^{1}$ zoe@facilitatewellbeing.com.mu, ${ }^{2} \mathrm{kmorganwelton@gmail.com}$

Article History:

Submit:

2021-12-30

Publish:

2022-02-28

\section{Abstract}

Trauma is a global phenomenon that affects millions each year. Recovery from trauma is challenging and approaches vary between cultures and models. Faith and spirituality have long-been traditional modes for healing in cultures worldwide. However, through a largely Westerndominated medical model of treatment, healing through religion and spirituality had been often overlooked in favor of medical diagnoses and psychiatric treatment. The ability to recover from traumatic circumstances and adversity is known as resilience. Yet there is limited research available on how faith and spirituality may build resilience in the aftermath of trauma and its application in developing countries, such as Cambodia. The aim of this qualitative study was to understand what factors, including faith and spirituality, had enabled the recovery from trauma of Cambodian young people, through the collection of their oral narratives. The young people reported that coping strategies, such as faith and spirituality, played a role in in transforming their lived traumatic experiences into strengths. This paper explores faith as a resilience factor and how faith and spirituality may support healing and positive-growth outcomes for young Cambodians recovering from trauma.

Keywords: Trauma; Faith and healing; Resilience; Cambodia 
Journal Homepage http://ijssr.net/index.php/ijssr

This is an Open Access article under the CC BY SA license

https://creativecommons.org/licenses/by-sa/4.0/

Published by Indonesian Academy of Social and Religious Research

\section{Introduction}

The majority of research on trauma and resilience in Cambodia has centred on the aftermath of the Khmer Rouge's (KR) genocide (1975-1979), which resulted in the Cambodian diaspora, widespread intergenerational trauma and a country challenged by high rates of poverty in the face of modern development. Due to Cambodia's recent traumatic history and the country's contemporary context, rates of trauma among children are higher than in other countries in Asia. Child abuse and neglect are commonplace in Cambodia, with research suggesting that maltreatment by parents and caregivers is an everyday occurrence for many Cambodian children. ${ }^{1}$ Furthermore, current estimates state that up to $90 \%$ of the current Cambodian population will experience at least one potentially traumatic event during their lifetime. ${ }^{2}$

Most research on trauma in Cambodia focusses on negative outcomes and primarily samples survivors of the KR era. Some have looked at positive outcomes among trauma survivors and look to find what builds resilience among trauma survivors. ${ }^{3}$ To understand how resilience develops, researchers have investigated factors facilitating resilience in children and young people to learn about the

1 Elizabeth Högger Klaus and Chhay Vivodin, "Parenting in Cambodia," https://www.ics.n1/public/ media-upload/Files/Report\%20Parenting\%20Seminar_March\%2021\%20Phnom\%20Penh_ICS\%20 RUPP.pdf; Glenn Miles and Nigel Thomas, "'Don't Grind an Egg against a Stone'—Children’s Rights and Violence in Cambodian History and Culture," Child Abuse Review: Journal of the British Association for the Study and Prevention of Child Abuse and Neglect 16, no. 6 (2007); L. Purnell, Transcultural Health Care: A Culturally Competent Approach (4th Ed.) (F. A. Davis, 2012); J. K. Reimer, "A System Just for Children: Voices of Child Victims and Witnesses About Their Experiences in the Cambodian Criminal Justice System," (Phnom Penh: Hagar International; UNICEF, 2015); J. K. Reimer et al., "The Road Home: Toward a Model of "Reintegration" and Considerations for Alternative Care for Children Trafficked for Sexual Exploitation in Cambodia," (Phnom Penh: Hagar International; World Vision Cambodia, 2007).

2 Richard F. Mollica et al., "The Enduring Mental Health Impact of Mass Violence: A Community Comparison Study of Cambodian Civilians Living in Cambodia and Thailand," International Journal of Social Psycbiatry 60, no. 1 (2014); T. Schunert et al., "Cambodian Mental Health Survey Report," Department of Psychology, Royal University of Phnom Penh (2012).

3 Inger Agger, "Calming the Mind: Healing after Mass Atrocity in Cambodia," Transcultural psychiatry 52, no. 4 (2015); Ann S. Masten, Ordinary Magic: Resilience in Development (Guilford Publications, 2015); Gwynyth Overland, Post Traumatic Survival: The Lessons of Cambodian Resilience (Phnom Penh: Cambridge Scholars Publishing, 2013). 
processes that support recovery post-trauma. ${ }^{4}$

Overland (2013) conducted qualitative research into the phenomena of resilience of KR survivors, in which certain themes emerged from the participants' interviews. ${ }^{5}$ These themes include social integration and having a strong work ethic, which are vital in building self-reliance, while religion and culture provide a knowledge-base and framework for understanding traumatic events from the KR era. ${ }^{6}$ Her study found that the more actively Cambodians were engaged in their culture and religion, the more they seemed to thrive. ${ }^{7}$ The narratives provided by these Cambodian trauma survivors are important, as few empirical studies have explored the underlying resilience factors in a predominately Buddhist population. Furthermore, the presence of traditional cultural and religious practices strengthened Cambodian trauma survivors' perceived identity and selfefficacy. ${ }^{8}$ It appeared that their beliefs, practices and culture helped them recover, but further research is required to see if the findings could be generalised to the broader Cambodian context, as the samples in these studies were limited to KR survivors. ${ }^{9}$

Cambodia is a country with deeply entrenched religious and spiritual beliefs. Cambodian citizens are granted religious freedom in The Constitution of the Kingdom of Cambodia. ${ }^{10}$ Traditional Cambodian religion is highly syncretic and integrates aspects of folk animism with Buddhism and Hinduism. Notably, the majority of Khmer have always had a strong sense of national identity, which is partially defined by the Cambodian's state official sanctioning of Buddhism. ${ }^{11}$ Current research suggests that more than $95 \%$ of the Cambodian

4 Ann S. Masten and Dante Cicchetti, "Resilience in Development: Progress and Transformation," (2016).

5 Overland, Post Traumatic Survival: The Lessons of Cambodian Resilience.

6 Ibid.

7 Ibid.

8 Agger, "Calming the Mind: Healing after Mass Atrocity in Cambodia."; Overland, Post Traumatic Survival: The Lessons of Cambodian Resilience; Gwynyth Jones Overland and Virak Yenn, "Generosity and Resilience: Transnational Activity among the Khmer of Norway," Refuge: Canada's Journal on Refugees (2007).

9 Agger, "Calming the Mind: Healing after Mass Atrocity in Cambodia."; Overland and Yenn, "Generosity and Resilience: Transnational Activity among the Khmer of Norway."

10 Cambodia Kingdom of, "Constitution of the Kingdom of Cambodia," (https:/www.refworld.org/ docid/3ae6b5a40.html, 1993).

11 May Mayko Ebihara, Svay: A Khmer Village in Cambodia (Cornell University Press, 1968); Charles F. Keyes, "Communist Revolution and the Buddhist Past in Cambodia," Asian visions of authority: Religion and the modern states of East and Southeast Asia (1994). 
population identifies as Theravada Buddhist ${ }^{12}$, which is significant as Buddhism was systematically dismantled by the Khmer Rouge during the 1970s only to re-emerge during the last 20 years. ${ }^{13}$ The remaining religious denominations of the Cambodian population are comprised of Muslims (largely the Cham ethnic minority), Christians, animist/folk religion and others. Even though Christianity is not considered a major religion in Cambodia ${ }^{14}$, evangelical churches claim their numbers are growing in Cambodia.

Multiple global studies conducted on predominately female trafficking victims found that within collectivist cultures, such as Cambodia, it was necessary for successful interventions to adopt a holistic, interdependent and interconnected approach to health and wellbeing to help trauma survivors build resilience. ${ }^{15}$ Importantly, this holistic approach to trauma intervention is less common in more widely established versions of trauma health and treatment in Western societies, which have autonomy, uniqueness and independent decision making as therapeutic goals in their approaches to trauma recovery. ${ }^{16}$ Many of these studies highlight that it is not only religion but also other spiritual beliefs that help people through traumatic experiences. ${ }^{17}$ Additionally, attending religious gatherings has been found to improve physical, social and emotional health. ${ }^{18}$

12 Alexandra Kent, "Reconfiguring Security: Buddhism and Moral Legitimacy in Cambodia," Security Dialogue 37, no. 3 (2006); Overland, Post Traumatic Survival: The Lessons of Cambodian Resilience.

13 Agger, "Calming the Mind: Healing after Mass Atrocity in Cambodia."

14 N. Adams, "Buddhism and Development: Communities in Cambodia Working as Partners," World Faith Development Dialogue, https://berkleycenter.georgetown.edu/publications/buddhism-anddevelopment-communities-in-cambodia-working-as-partners.

15 Noel B. Busch-Armendariz, Maura B. Nsonwu, and Laurie Cook Heffron, "Human Trafficking Victims and Their Children: Assessing Needs, Vulnerabilities, Strengths, and Survivorship," Journal of Applied Research on Children: Informing Policy for Children at Risk 2, no. 1 (2011); Sarah K. Ladd and Laurel Neufeld Weaver, "Moving Forward: Collaborative Accompaniment of Human Trafficking Survivors by Using Trauma-Informed Practices," Journal of human trafficking 4, no. 3 (2018); Jordan J. Steiner et al., "Providing Services to Trafficking Survivors: Understanding Practices across the Globe," Journal of evidence-informed social work 15, no. 2 (2018).

16 Ladd and Neufeld Weaver, "Moving Forward: Collaborative Accompaniment of Human Trafficking Survivors by Using Trauma-Informed Practices."

17 Linda K. George et al., "Spirituality and Health: What We Know, What We Need to Know," Journal of social and clinical psychology 19, no. 1 (2000); Lauren E. Maltby and Todd W. Hall, "Trauma, Attachment, and Spirituality: A Case Study," Journal of Psychology and Theology 40, no. 4 (2012); William Yule et al., "Children in Armed Conflict," in Trauma Interventions in War and Peace, ed. B. L. Green, et al. (Kluwer Academic/Plenum Publishers, 2003).

18 Linda M. Chatters et al., "Social Support from Church and Family Members and Depressive Symptoms among Older African Americans," The American Journal of Geriatric Psychiatry 23, no. 6 (2015); Neal Krause, "Church-Based Social Support and Health in Old Age: Exploring Variations by Race,” The Journals of Gerontology Series B: Psychological Sciences and Social Sciences 57, no. 6 (2002). 
Furthermore, significant research conducted over the last two decades there has been extensive research conducted on the link between prayer and wellbeing, yet the results are inconsistent at best.

One study found that Cambodian refugees involved with prayer and religious activities were one-third less likely to meet the criteria for PTSD than those who participated in fewer to no religious activities. ${ }^{19}$ Although there is no clear, universally agreed-upon explanation as to how religious beliefs shape responses to healing, there have been studies ${ }^{20}$ that link the relationship between prayer, meditation and spiritual practices to healing from trauma in the Cambodian context. In particular, the practice of ancestor worship, performing meritorious acts (like donating money to the temple) and the emphasis on meditative mindfulness are believed to foster overall wellbeing among Buddhists in Cambodia. ${ }^{21}$

Ceremonies and ritualised practices of religion and culture are often cited as underpinning resilience factors, as they provide a transformative epiphany where individuals are able to experience a surge of hope or belief that life can be meaningful. ${ }^{22}$ There has been limited research into how Buddhist and animistblended belief systems like the one in Cambodia directly affect an individual's resilience. However, Chhim found that Cambodians were able to make sense and reconcile the lived experiences of genocide, torture and violence that their country witnessed during the 20th century by using supernatural forces such as animistic spirits as a way to understand these atrocities. ${ }^{23}$ Although more research on the role of animistic beliefs in being a protective factor of recovery from trauma in Cambodia is needed, Chhim (2013) found that the role of religious fusion,

19 Richard F. Mollica, David C. Henderson, and Svang Tor, "Psychiatric Effects of Traumatic Brain Injury Events in Cambodian Survivors of Mass Violence," The British Journal of Psychiatry 181, no. 4 (2002).

20 Agger, "Calming the Mind: Healing after Mass Atrocity in Cambodia."; Amy L. Ai, Christopher Peterson, and Bu Huang, "The Effect of Religious-Spiritual Coping on Positive Attitudes of Adult Muslim Refugees from Kosovo and Bosnia," The International Journal for the Psychology of Religion 13, no. 1 (2003); N. Barker and P. Braeunlein, "Ritual, Pain, and the Religious Body in Southeast Asia," (European Society for the Study of Southeast Asia, SOAS, 2001); Devon E. Hinton et al., "Acceptance and Mindfulness Techniques as Applied to Refugee and Ethnic Minority Populations with Ptsd: Examples from" Culturally Adapted Cbt"," Cognitive and Behavioral Practice 20, no. 1 (2013).

${ }^{21}$ Chamlong Disayavanish et al., "A Buddhist Approach to Suicide Prevention," J Med Assoc Thail 90, no. 8 (2007); Marta Elliott and Michael J. Doane, "Religion, Psychological Well-Being, and Health," in Encyclopedia of Quality of Life and Well-Being Research, ed. Alex C. Michalos (Dordrecht: Springer Netherlands, 2014); Roberta R. Greene, "Resilience and Healing among Cambodian Survivors of the Khmer Rouge Regime," Journal of evidence-informed social work 12, no. 6 (2015).

22 Masten, Ordinary Magic: Resilience in Development.

23 Sotheara Chhim, "Baksbat (Broken Courage): A Trauma-Based Cultural Syndrome in Cambodia," Medical Anthropology 32, no. 2 (2013). 
faith practices and animism can help foster resilience among Cambodian trauma survivors. ${ }^{24}$

In Cambodia, Buddhist practices centre around the individual giving donations to monks, leaving out offerings to ancestors in their homes and meditating. ${ }^{25}$ Elliot and Hayward (2009) have suggested that it is in the partaking of these Buddhist rituals, which often involve being of service to the community, that people are led to heightened self-esteem and sense of wellbeing. ${ }^{26}$ Alternatively, Christians often develop their own communities that are separate and apart from the Buddhist-oriented villages. However, Masten (2015) proposes that religious faith has the potential to build a sense of cultural identity, which works as a protective factor by fostering positive identification with a newly found religion post-trauma. ${ }^{27}$ Accordingly, the role of faith and religious communities in fostering social connectedness were identified as potentially important protective factors for building resilience from trauma in the Cambodian context. ${ }^{28}$ As seen, during the $21^{\text {st }}$ century, there has been a resurgence in interest in the phenomenon of resilience with faith as an underpinning factor. This study aims to fill a gap in the literature by focussing on the role of faith in the resilience of young Cambodian trauma survivors who are at least one generation removed from the KR era.

\section{Method}

This study sought to understand factors promoting the recovery and wellbeing of young Cambodian trauma survivors. The approach was to explore the lived experiences and individual narrative constructions of the young people's recovery and their lives as they are now. To do this, open-ended questions in a semi-structured interview were used, as they could provide important insights into resilience and wellbeing that quantitative methods could not capture. ${ }^{29}$ The reason for gathering biographical narratives is not to make sense of a person's life, but rather to learn about their lived experiences of recovery and healing. ${ }^{30} \mathrm{As}$ such, an exploratory case study design was used.

24 Ibid.

25 Ian Harris, Cambodian Buddhism (University of Hawaii Press, 2008).

${ }^{26}$ Marta Elliott and R. David Hayward, "Religion and Life Satisfaction Worldwide: The Role of Government Regulation," Sociology of Religion 70, no. 3 (2009).

27 Masten, Ordinary Magic: Resilience in Development.

28 S. Miles et al., The Butterfly Longitudinal Research Project: End of Year Progress Report 2020 (Chab Dai Coalition, 2020).

29 Robert J. Wright, Research Methods for Counseling: An Introduction (SAGE Publications, 2014).

30 Agger, "Calming the Mind: Healing after Mass Atrocity in Cambodia."; Gwynyth Overland, "Generating Theory, Biographical Accounts and Translation: A Study of Trauma and Resilience," International Journal of Social Research Methodology 14, no. 1 (2011). 
Recruitment for this study began after ethical approval was obtained by Deakin University Human Research Ethics Committee and the Cambodian Ministry of Health. A flyer was disseminated and a presentation on the research project was delivered to participating non-government organisations (NGOs) which are outlined below. This flyer was translated into Khmer and briefly outlined the purpose of this study and invited candidates to participate. Participants had to fulfil a set of verifiable selection criteria. All participants in this study were aged between 18 to 30 years old, were recruited from three participating NGOs, were living independently and either employed or in some type of education program. Participants meeting these criteria, were identified by NGO insiders as "doing well" therefore demonstrating resilience.

Maintaining the anonymity of participants in this study was of upmost importance. The NGO community in Cambodia is diverse, however, NGOs are largely interconnected, especially those working within the child protection sector. The three Cambodian NGOs from which the young people were recruited are Hagar International (Hagar), This Life Cambodia (TLC) and Flame Cambodia (Flame). All three NGOs provide different supports and aftercare services to trauma survivors. Both Hagar and Flame are Christian and faith-based NGOs whilst TLC is non-denominational. All three NGOs work in providing advocacy, empowerment, education and training opportunities and psychosocial services for the beneficiaries they serve.

The participating NGOs in this study played a vital role in the recruitment process, as in the initial stages key insiders from the NGOs were utilized to identify prospective study participants. The majority of key insiders within the NGOs were social work educated, so there was significant discussion about how they defined both resilience and doing well with former beneficiaries. These discussions were initially held as interactive workshops, presenting the research at the same time as disseminating the flyer. Key insiders identified potential participants that they believed to be doing well as being employed or studying, having created families of their own and participating in their communities with existing social networks.

Research questions pertaining to lived human experiences necessitate cognitive elements of memories, intentions, perceptions, understandings and constructions that only a qualitative approach can adequately capture. As elements of individual construction of reality are influenced by unique sociocultural constructs, in addition to environmental factors such as community and family, quantitative tools are generally not able to capture human nuances relevant to answering research questions of this nature. Accordingly, there is no singular 
underlying reality for the young people who participated in this study and "truth" can be sought through various sources of evidence.

Multiple studies have combined qualitative and analytic techniques, arguing it is possible to produce a multidimensional understanding of data ${ }^{31}$, which was the goal of this research. As such, this project combined a biographical interpretive method with Cambodian trauma survivors in the form of a one-hour interview, supported by a timeline and resilience scale. ${ }^{32}$

Utilising an integrated approach allowed for a layered and complex understanding of resilience to emerge from the data. The triangulation of data was iterative rather than linear, so moving back and forth between the data collection strategies is imperative. ${ }^{33}$ As such, multiple data collection tools, when combined, enable broader patterns to emerge. The rationale for the research paradigm, epistemology, methodology and methods used in the study are detailed in Table 1 below.

\section{Table 1: Rationale for Research}

\begin{tabular}{|c|c|c|c|}
\hline Paradigm & Epistemology & Methodology & Methods \\
\hline $\begin{array}{l}\text { Constructivist } \\
\text { rationale: } \\
\text { construct a system } \\
\text { of meaning and } \\
\text { discourse by } \\
\text { exploring the } \\
\text { narrative } \\
\text { constructions and } \\
\text { explanations of } \\
\text { participant's lived } \\
\text { experiences of } \\
\text { recovery from } \\
\text { trauma. }\end{array}$ & $\begin{array}{l}\text { rationale: } \\
\text { "truth" can be sought } \\
\text { through various } \\
\text { sources of evidence } \\
\text { in relation to a } \\
\text { storyline captured in } \\
\text { the young people's } \\
\text { narratives. }\end{array}$ & $\begin{array}{l}\text { Case study design } \\
\text { rationale: } \\
\text { Allows for } \\
\text { descriptive accounts } \\
\text { of social interactions, } \\
\text { meaning making and } \\
\text { interpretation } \\
\text { The qualitative } \\
\text { approach is the } \\
\text { preferred method of } \\
\text { learning about the } \\
\text { social world. }\end{array}$ & $\begin{array}{l}\text { Semi-structured } \\
\text { interviews rationale: } \\
\text { Biographical } \\
\text { interpretive method that } \\
\text { quantitative methods } \\
\text { cannot capture } \\
\text { Focus on the } \\
\text { participant's life, rather } \\
\text { than their trauma } \\
\text { history. }\end{array}$ \\
\hline $\begin{array}{l}\text { Constructivism } \\
\text { recognizes the } \\
\text { importance of the } \\
\text { subjective human } \\
\text { creation of meaning, } \\
\text { but doesn't reject } \\
\text { outright some notion } \\
\text { of objectivity }\end{array}$ & $\begin{array}{l}\text { Phenomenological } \\
\text { position and } \\
\text { reflexivity of the } \\
\text { researcher unpacked } \\
\text { in researcher } \\
\text { assumptions. }\end{array}$ & $\begin{array}{l}\text { Grounded Theory } \\
\text { rationale: } \\
\text { Inductive technique } \\
\text { multidimensional } \\
\text { understanding of } \\
\text { data. }\end{array}$ & $\begin{array}{l}\text { Resilience scale } \\
\text { rationale: The self- } \\
\text { assessment/interpretive } \\
\text { method supported } \\
\text { other sources of data } \\
\text { collected. }\end{array}$ \\
\hline $\begin{array}{l}\text { A Constructivist } \\
\text { approach is closely } \\
\text { tied to different } \\
\text { visions of how social } \\
\text { reality should be } \\
\text { studied. }\end{array}$ & $\begin{array}{l}\text { Co-creation of } \\
\text { knowledge through } \\
\text { naturalistic enquiry } \\
\text { allows for a layered } \\
\text { and complex } \\
\text { understanding of } \\
\text { resilience and } \\
\text { recovery from trauma } \\
\text { to emerge. }\end{array}$ & $\begin{array}{l}\text { Thematic Analysis } \\
\& \text { GT integration } \\
\text { rationale: } \\
\text { Different interpretive } \\
\text { scopes on meaning } \\
\text { making which } \\
\text { provides alternate } \\
\text { vantage points } \\
\text { through a } \\
\text { constructivist } \\
\text { perspective. }\end{array}$ & $\begin{array}{l}\text { Narrative timelines } \\
\text { rationale: } \\
\text { Narrative timelines may } \\
\text { build rapport, utilising } \\
\text { participants as } \\
\text { navigators, allowing for } \\
\text { therapeutic moments } \\
\text { with positive closure. }\end{array}$ \\
\hline \multicolumn{4}{|c|}{$\begin{array}{l}\text { Outcome } \\
\end{array}$} \\
\hline $\begin{array}{l}\text { Provides a } \\
\text { conceptual } \\
\text { framework. }\end{array}$ & $\begin{array}{l}\text { Reflective practice is } \\
\text { embedded in the } \\
\text { research process. }\end{array}$ & $\begin{array}{l}\text { Systematic theory } \\
\text { generation which } \\
\text { represented the } \\
\text { phenomena of } \\
\text { interest. }\end{array}$ & $\begin{array}{l}\text { Multiple sources of data } \\
\text { used to maintain rigour } \\
\text { through reliability and } \\
\text { validity. }\end{array}$ \\
\hline
\end{tabular}

31 Jerry Floersch et al., "Integrating Thematic, Grounded Theory and Narrative Analysis: A Case Study of Adolescent Psychotropic Treatment," Qualitative Social Work 9, no. 3 (2010).

32 Zoe Wyatt, "Pathways of Resilience and Recovery from Trauma for Cambodian Young People," Advances in Social Science and Culture 3 (2021).

${ }^{33}$ Janice M. Morse et al., "Verification Strategies for Establishing Reliability and Validity in Qualitative Research," International journal of qualitative methods 1, no. 2 (2002). 
In the process of transcribing interview data, an interest in participant language and terminology used to describe particular emotional states began to emerge. An explanation of how recovery factors worked in the lives of the participants was found in the conceptualisation of ideas embedded in the vocabulary of everyday life. These ideas can be accessed through the use of language. A worldview that dealt with the problem of hardships was conveyed to them through their everyday language. The findings of this study show a certain way of viewing life, which reflects certain values.

The next section introduces some of the findings through the narratives of the young people by providing cultural context and direct quotes about their faith, spirituality and recovery from trauma. Participant narratives are attributed to an anonymised name in the following section, followed by their gender. Participant interviews conducted in English are marked with (E) and have not been changed grammatically in any way, so as to maintain the integrity of the data. Interviews translated from Khmer are marked with $(\mathrm{T})$ and correct English grammar has been applied during the translation and back translation process.

\section{Findings}

The findings presented below explore how spirituality, faith and religious communities helped the young people recover from trauma and build resilience. Importantly, almost all of the participant interviews attributed their faith and religious practices to their families. For some participants, their families who influenced their faith were their foster families; for other they were their families of origin. Participants from non-faith-based TLC all self-identified as Buddhist and linked their faith to honouring their families and communities. For this group, who had all been incarcerated in prison as children, the main faith-based resilience factors were stability, sense of belonging and connection to something bigger than themselves through their families and communities. This was in direct contrast to participants from a faith-based Hagar and Flame, who selfidentified as Christian, with only one identifying as Buddhist and one identifying as non-religious. Unlike the Christian participants, the Buddhist young people often expressed ambivalence in terms of why they were Buddhist. Almost all of these participants made reference to being Buddhist because their families were Buddhist: 
"I am a Buddhist. Although I'm not sure though why I believe in this religion. For one thing, my whole family follows this faith. We always to go pagoda during New Year and Pchum Ben." - Bourey, M (T)

"Basically, it is ... respect your parents, do good deeds and then there's a little bit of magic."-Bunroeun, $M(T)$

For many of the young people, finding meaning through faith coincided with their finding meaningful connection with others through their faith communities, often facilitated by their families. The majority of the young people from Hagar and Flame often self-identified as Christian before any questions regarding faith had been asked. Most were introduced to Christianity at an early age through their foster families, who also introduced them to church and the Christian community. For many of the young people, going to church and being part of the Christian community provided a support system, sense of belonging and connection with others never before experienced:

"I can say it was a good community where everyone looks after everyone. When you have troubles, the group leader, they call and ask for everyone to come and pray. Is good you know, the support." - Sothea, $M(E)$

In addition to finding a sense of belonging afforded by their faith communities, many of the young people from Hagar and Flame connected their belief in the Christian God to their behaviour changing. For example, some described how their connection to faith helps them feel better equipped to handle life's challenges with patience, tolerance and acceptance:

"God changed my behaviour and my practice. When I thought about God in my mind, he made me more tolerant and committed. Before I trust in God, my behaviour is not like now. I have not much tolerance and could not manage my anger. My life always met a lot of troubles." - Chivy, $F(E)$

"I think when I believe in God, I feel free. I feel free, not stressed a lot and every time when I pray hard and keep praying, there's an answer for me. So, if there's an answer, I still keep my believing, my faith because he always answers me when I knock the door." - Socheata, F (E)

Many of the Christian young people spoke about the sense of peace their faith brought them, indicating the role of faith as a coping mechanism in regulating 
emotions. Importantly, it was their finding meaning through faith that gave these young people some relief from negative emotions, such as sadness and anger:

"I used to feel sad a lot; I sometimes have difficulty breathing. I always have a lot of questions in my mind, 'Why there is me? Why there is Earth? Why we have people?' Then I joined the children group, they gave me all the answers and I started to understand and read Bible and then it made me believe God." Chanmony, F (E)

"Since I have trust in God, my life has become better, I realised. I can manage my anger and pressure." - Chenda, F (E)

Most of the young people found faith as a way of handling challenges in life. The role that faith played in the young people's recovery from trauma is particularly significant for the orphans, who lacked parental guidance and spent many years living on the streets. Where they lacked their parents to rely on, their faith in and reliance on God gave them some peace. Chivy explained:

"I go to church to listen to the word of God. I try to follow what God says and teaches. So, most of the time, I am [now] more patient. Now even though they speak bad words about me, I can just ignore and just forgive them as God [would have me do]. Now I also feel more at peace with my past life. I have much more patience." - Chivy, F (T)

Christian faith and the conception of God as "the Father" had a powerful impact on the majority of the orphaned young people's journey of recovery. Before finding their Christian faith, many of these young people lacked the presence of a father in their lives. Their faith and ability to find a God to fill that absence may have acted as a replacement father helping them create meaning in their lives. Samnang and Kunthea described how finding God as the father and belonging through faith was particularly meaningful for them:

"I'm not sure when [I started to believe in God], but I can say it's not in the village at that time. I can say when I heard the word 'father.' Because in the song, it says, 'God is the Father.' And sometimes I'm wondering about the word 'father.' A lot of, I can say, a lot of explanation about what is father, God is father. And I find out, I feel I have a father. And also, he loves me, so I accepted him." Samnang, F (E) 
"Before I know Jesus, I looked at the sky and said if there was a real God, please take me out from that family [where I was trafficked to]. And then my life changed. God is good for me like the father I never had. I keep him in my mind always." - Kunthea, F (E)

For many of the young people, in addition to faith in God, the power of prayer was also a central theme in faith helping build resilience. Prayer for these young people seemed to help them facilitate control over their own lives. Comments such as, "I prayed and I prayed and I prayed and God gave me an iPhone," (Chamroeun) seemed to suggest that through enough prayer, one could elicit God's help and ask him to grant you what you needed:

"My mother got a breast problem. She hurt too much, and I prayed for her. After that day, she said that, 'I feel great. My breasts are not hurting anymore." - Socheata, F (E)

"When I pray, I see a sign. I want to visit a beach. I'd never been to a beach, a zoo, and I want to visit Angkor Wat. So, I prayed and within one week, I got to go to those places because I pray to God." - Chanvatey, M (E)

"I asked God to let me pass because I was a low student and because the exam at that time was very hard and those who can't pass the exam won't get to go to Grade 10. Thank God, I passed the exam." - Chanlina, F (E)

Many of the Christian young people spoke of concepts like: "trust in God"; "being on God's path"; and "helping others because that is what God wants from us" as central to their stories of recovery and their finding meaning posttrauma. Chanlina considered that it was an act of God and not her hard work and dedication to her studies that resulted in her passing the exam. This was a reoccurring theme and pattern of behaviour. In instances where the young people had worked very hard to achieve something in life, be it scholarships, careers, relationships, etc., the young people of faith largely attributed their successes to God's will rather than their own merit:

"I have everything nowadays because God gives it to me." - Charya, M (E)

"God has changed my life a lot. Before I become Christian my life was totally different. I am a good Christian now. I go to church, I pray, I read the Bible. It belps me very much." - Sothea, $\mathrm{M}(\mathrm{E})$ 


\section{Discussion}

In the backdrop of Cambodia's deeply spiritual roots, faith-based practices appeared to have a positive impact on the young trauma survivors. Because of this, some found comfort and solace in their faith, which for some pre-existed and for others was newly found. For these young people, the difficulties and challenges in one's life could be met with prayer and a little bit of "magic." Furthermore, these participants also partially attributed their motivation to recover from past trauma and thrive in life to either being on God's path or supernatural forces. These individuals felt that they were predestined to succeed due to external forces. Moreover, they were able to reframe their trauma histories as both meaningful and necessary within this context. The role of faith appeared to have a direct correlation with the success of the young people's ability to positively adapt despite the adversity they experienced.

Many of the young people recovering from trauma described the reconstruction of their personal identities post-trauma and their attempts to integrate their adverse experiences into a positive framework while also realigning and reclaiming aspects of deeply entrenched morally acceptable sociocultural norms. ${ }^{34} \mathrm{~A}$ number of researchers assert that the transformation of trauma experiences through mental reframing can create key cognitive shifts. ${ }^{35}$ These shifts, or critical turning points, can emerge in response to future challenges ${ }^{36}$, which is consistent with the findings of this study. In a study ${ }^{37}$ on turning points in the healing process of childhood sexual abuse survivors, researchers identified three broad categories of turning points: 1) influential relationships (interpersonal and professional); 2) insight and new meanings (cognitive shifts and faith experiences); and 3) transparent communication with others regarding personal trauma histories (i.e., sharing their experiences with trusted individuals). Furthermore, a literature review on the psychology of religion conceptualised

${ }^{34}$ Zoe Wyatt, "Dynamism: Reconceptualising Resilience in Recovery from Trauma," Asian Journal of Social Science Studies 6, no. 4 (2021).

35 Charles S. Carver et al., "How Coping Mediates the Effect of Optimism on Distress: A Study of Women with Early Stage Breast Cancer," (1999); Richard G. Tedeschi and Lawrence G. Calhoun, "The Posttraumatic Growth Inventory: Measuring the Positive Legacy of Trauma," Journal of traumatic stress 9, no. 3 (1996).

36 Jennifer Dagg and Jane Gray, "Turning Points and Critical Moments in Resilient European Lives: A Biographical Longitudinal Analysis," in Poverty, Crisis and Resilience (Edward Elgar Publishing, 2020).

37 Scott D. Easton et al., "Posttraumatic Growth among Men with Histories of Child Sexual Abuse," Child maltreatment 18, no. 4 (2013). 
religious experience with social psychology and found that wellbeing was enhanced by religious and spiritual practices. ${ }^{38}$

This study's findings that faith was a coping strategy in recovery from trauma is consistent with the literature on spirituality and resilience which states that faith can be cultivated and used as a tool to build resilience upon everyday experiences. ${ }^{39}$ Tillich (1957) describes deliberate and conscious acts of faithbased rituals and behaviours, which he argues are immersed in the unconscious elements of the personality. ${ }^{40}$ Courage and spiritual principles appeared to guide some participants' behaviour as well as providing comfort and support in both good times and bad. For many of the individualist young people, it was their prayers to God that helped them navigate through their negative emotions in their recovery from trauma. Cognitive aspects of prayer may serve to connect a person with their spiritual condition, relational life, or find the presence of God in upward prayer. $^{41}$

It appeared that for the young people in this study, their self-sufficiency and motivational drive was cultivated through prayer, essentially placing God in control by centring themselves from a place of God-sufficiency. Moreover, the humble nature of most of these participants strongly suggests that they did not credit their survival and success in life to anything they had instigated, rather, that God or some type of magic had been at play. Consequently, the internal dialogue that the young people used to describe prayer, magic and God was inexplicably intertwined and influenced by Cambodian culture.

There is a common expression in Cambodia which states that "to be Cambodian is to be Buddhist". ${ }^{42}$ Yet even historically, Cambodians have been noted to be more flexible with their practice of Theravada Buddhism. ${ }^{43}$ The unique blends of religion found in Cambodia dialectically integrate aspects of seemingly opposing religious systems and traditions. This includes the dominant religion of Theravada Buddhism, older forms of folk animism and also accounts

38 Robert A. Emmons and Raymond F. Paloutzian, "The Psychology of Religion," Annual review of psychology 54, no. 1 (2003).

39 Özlem Ögtem-Young, «Faith Resilience: Everyday Experiences,» Societies 8, no. 1 (2018).

40 Paul Tillich, Dynamics of Faith (New York: HarperCollins, 1957).

${ }^{41}$ Meleah Ladd et al., "Inward, Outward, Upward Prayer and Big Five Personality Traits," Archive for the Psychology of Religion 29, no. 1 (2007).

42 J. Ledgerwood, "Buddhist Practice in Rural Kandal Province, 1960 and 2003: An Essay in Honor of May M. Ebihara," in People of Virtue: Reconfiguring Religion, Power and Moral Order in Cambodia Today, ed. Alexandra Kent and David Chandler, Nordic Institute of Asian Studies - Studies in Asian Topics (Copenhagen: NIAS Press, 2008), 4.

43 Ebihara, Svay: A Khmer Village in Cambodia. 
for the rise of Christianity. Western conceptualisations of both Buddhism and Christianity can be more formalised than the flexibility of religious faith and practice captured in the young people's accounts. Some participants reported to be both Buddhist and Christian, whilst many believed in magic (an aspect of animistic traditions). Furthermore, findings from this study suggested that many of the young people had developed a moral framework and sense of hope from their faiths. Faith was also utilised as a coping strategy by many of the young people to sustain themselves psychologically, socially and spiritually.

The element of magic was evidenced in the oral narratives of many participants across both Christian and Buddhist groups. For these young people, coming from a cultural foundation of animistic beliefs, when coupled with the rise of American Evangelism and opportunities for economic advancement, it appeared that for some, the result of prayer to a Christian God was a form of magic. For many of the Christian Cambodians in this study, prayer could operate like magic, such as "I prayed and I prayed and I prayed and God gave me an iPhone" (Chamroeun). This conceptualisation of God as a quasi-magical, wishgranting entity is informed by a combination of $21^{\text {st }}$-century globalised capitalism and Cambodia's roots in folk animism with its emphasis on the spirit world. This underlying theme of magic and animism being prevalent in contemporary Cambodian society and culture also influences Cambodian Buddhist worldviews. This emerged in a participant interview when the participant described Buddhism as, "Basically, it is ... respect your parents, do good deeds and then there's a little bit of magic" (Bunroeun). This suggests that superstition and magic are deeply entrenched in the collective cultural Cambodian psyche regardless of faith background, making it a relevant factor to consider in future resilience studies involving trauma survivors in Cambodia.

\section{Conclusion}

This research explored what recovery looks like for Cambodian young people who experienced early childhood trauma and the role of resilience and how faith informs resilience. Particular attention was given to how individual responses and coping styles played a role in developing resilience and meaning post-trauma. This study found that meaning constructed through faith was a strong theme, with faith often underpinning a participant's overall sense of wellbeing. Research participants found comfort and solace in their faith and religious practices as a way of navigating negative emotions and understanding what had happened to 
them. ${ }^{44}$ Furthermore, many of the participants described how they found a sense of belonging through social connectedness in their faith communities, which influenced their resilience and wellbeing. Moreover, many of the young people were able to create meaning post-trauma through the lens of their faith.

\section{Ethics and Acknowledgements}

This article stems from $\mathrm{PhD}$ research that obtained ethics approval from both Deakin University Human Research Ethics Committee and the Cambodian Ministry of Health. The researcher is a member of the Australian Association of Social Workers and was assisted by her Deakin University academic supervisors, Associate Professor Elizabeth Hoban and Associate Professor Petra Staiger.

\section{References}

Adams, N. "Buddhism and Development: Communities in Cambodia Working as Partners." World Faith Development Dialogue, https://berkleycenter. georgetown.edu/publications/buddhism-and-development-communitiesin-cambodia-working-as-partners.

Agger, Inger. "Calming the Mind: Healing after Mass Atrocity in Cambodia." Transcultural psychiatry 52, no. 4 (2015): 543-60.

Ai, Amy L., Christopher Peterson, and Bu Huang. "The Effect of ReligiousSpiritual Coping on Positive Attitudes of Adult Muslim Refugees from Kosovo and Bosnia." The International Journal for the Psychology of Religion 13, no. 1 (2003): 29-47.

Barker, N., and P. Braeunlein. "Ritual, Pain, and the Religious Body in Southeast Asia." European Society for the Study of Southeast Asia, SOAS, 2001.

Busch-Armendariz, Noel B., Maura B. Nsonwu, and Laurie Cook Heffron. "Human Trafficking Victims and Their Children: Assessing Needs, Vulnerabilities, Strengths, and Survivorship." Journal of Applied Research on Children: Informing Policy for Children at Risk 2, no. 1 (2011): 3.

Carver, Charles S., Christina Pozo, Suzanne D. Harris, Victoria Noriega, Michael F. Scheier, David S. Robinson, Alfred S. Ketcham, Frederick L. Moffat Jr, and Kimberley C. Clark. "How Coping Mediates the Effect of Optimism on Distress: A Study of Women with Early Stage Breast Cancer.” (1999).

${ }^{44}$ Wyatt, "Pathways of Resilience and Recovery from Trauma for Cambodian Young People." 
Chatters, Linda M., Robert Joseph Taylor, Amanda Toler Woodward, and Emily J. Nicklett. "Social Support from Church and Family Members and Depressive Symptoms among Older African Americans." The American Journal of Geriatric Psychiatry 23, no. 6 (2015): 559-67.

Chhim, Sotheara. "Baksbat (Broken Courage): A Trauma-Based Cultural Syndrome in Cambodia." Medical Anthropology 32, no. 2 (2013): 160-73.

Dagg,Jennifer, and Jane Gray. "Turning Points and Critical Moments in Resilient European Lives: A Biographical Longitudinal Analysis.” In Poverty, Crisis and Resilience: Edward Elgar Publishing, 2020.

Disayavanish, Chamlong, Primprao Disayavanish, Tala Thammaroj, Surut Jianmongkol, Kimaporn Kamanarong, and Somjit Prueksaritanond. "A Buddhist Approach to Suicide Prevention.” J Med Assoc Thail 90, no. 8 (2007): 1680-88.

Easton, Scott D., Carol Coohey, Alison M. Rhodes, and M. V. Moorthy. "Posttraumatic Growth among Men with Histories of Child Sexual Abuse." Child maltreatment 18, no. 4 (2013): 211-20.

Ebihara, May Mayko. Svay: A Khmer Village in Cambodia. Cornell University Press, 1968.

Elliott, Marta, and Michael J. Doane. "Religion, Psychological Well-Being, and Health." In Encyclopedia of Quality of Life and Well-Being Research, edited by Alex C. Michalos, 5469-74. Dordrecht: Springer Netherlands, 2014.

Elliott, Marta, and R. David Hayward. "Religion and Life Satisfaction Worldwide: The Role of Government Regulation.” Sociology of Religion 70, no. 3 (2009): 285-310.

Emmons, Robert A., and Raymond F. Paloutzian. "The Psychology of Religion.” Annual review of psychology 54, no. 1 (2003): 377-402.

Floersch, Jerry, Jeffrey L. Longhofer, Derrick Kranke, and Lisa Townsend. "Integrating Thematic, Grounded Theory and Narrative Analysis: A Case Study of Adolescent Psychotropic Treatment." Qualitative Social Work 9, no. 3 (2010): 407-25.

George, Linda K., David B. Larson, Harold G. Koenig, and Michael E. McCullough. "Spirituality and Health: What We Know, What We Need to Know." Journal of social and clinical psychology 19, no. 1 (2000): 102-16.

Greene, Roberta R. "Resilience and Healing among Cambodian Survivors of the Khmer Rouge Regime." Journal of evidence-informed social work 12, no. 6 (2015): 579-87. 
Harris, Ian. Cambodian Buddhism. University of Hawaii Press, 2008.

Hinton, Devon E., Vuth Pich, Stefan G. Hofmann, and Michael W. Otto. "Acceptance and Mindfulness Techniques as Applied to Refugee and Ethnic Minority Populations with Ptsd: Examples from” Culturally Adapted Cbt"." Cognitive and Behavioral Practice 20, no. 1 (2013): 33-46.

Kent, Alexandra. "Reconfiguring Security: Buddhism and Moral Legitimacy in Cambodia." Security Dialogue 37, no. 3 (2006): 343-61.

Keyes, Charles F. "Communist Revolution and the Buddhist Past in Cambodia." Asian visions of authority: Religion and the modern states of East and Southeast Asia (1994): 43-73.

Kingdom of, Cambodia. "Constitution of the Kingdom of Cambodia." https:// www.refworld.org/docid/3ae6b5a40.html, 1993.

Klaus, Elizabeth Högger, and Chhay Vivodin. "Parenting in Cambodia." https://www.ics.nl/public/media-upload/Files/Report\%20Parenting\%20 Seminar_March\%2021\%20Phnom\%20Penh_ICS\%20RUPP.pdf.

Krause, Neal. "Church-Based Social Support and Health in Old Age: Exploring Variations by Race.” The Journals of Gerontology Series B: Psychological Sciences and Social Sciences 57, no. 6 (2002): S332-S47.

Ladd, Meleah, Kevin Ladd, Ted Swanson, Julie Harner, Kate St Pierre, Tricia Metz, and Danielle Trnka. "Inward, Outward, Upward Prayer and Big Five Personality Traits.” Archive for the Psychology of Religion 29, no. 1 (2007): 151-75.

Ladd, Sarah K., and Laurel Neufeld Weaver. "Moving Forward: Collaborative Accompaniment of Human Trafficking Survivors by Using TraumaInformed Practices.” Journal of human trafficking 4, no. 3 (2018): 191-212.

Ledgerwood, J. "Buddhist Practice in Rural Kandal Province, 1960 and 2003: An Essay in Honor of May M. Ebihara." In People of Virtue: Reconfiguring Religion, Power and Moral Order in Cambodia Today, edited by Alexandra Kent and David Chandler. Nordic Institute of Asian Studies - Studies in Asian Topics, 47. Copenhagen: NIAS Press, 2008.

Maltby, Lauren E., and Todd W. Hall. "Trauma, Attachment, and Spirituality: A Case Study." Journal of Psychology and Theology 40, no. 4 (2012): 302-12.

Masten, Ann S. Ordinary Magic: Resilience in Development. Guilford Publications, 2015.

Masten, Ann S., and Dante Cicchetti. "Resilience in Development: Progress and Transformation.” (2016). 
Miles, Glenn, and Nigel Thomas. "Don't Grind an Egg against a Stone'Children's Rights and Violence in Cambodian History and Culture." Child Abuse Review: Journal of the British Association for the Study and Prevention of Child Abuse and Neglect 16, no. 6 (2007): 383-400.

Miles, S., S. Heang, V. Lim, C. Nhanh, and P. Sreang. The Butterfy Longitudinal Research Project: End of Year Progress Report 2020. Chab Dai Coalition, 2020.

Mollica, Richard F., Robert Brooks, Svang Tor, Barbara Lopes-Cardozo, and Derrick Silove. “The Enduring Mental Health Impact of Mass Violence: A Community Comparison Study of Cambodian Civilians Living in Cambodia and Thailand." International Journal of Social Psychiatry 60, no. 1 (2014): 6-20.

Mollica, Richard F., David C. Henderson, and Svang Tor. "Psychiatric Effects of Traumatic Brain Injury Events in Cambodian Survivors of Mass Violence." The British Journal of Psychiatry 181, no. 4 (2002): 339-47.

Morse, Janice M., Michael Barrett, Maria Mayan, Karin Olson, and Jude Spiers. "Verification Strategies for Establishing Reliability and Validity in Qualitative Research.” International journal of qualitative methods 1, no. 2 (2002): 13-22.

Ögtem-Young, Özlem. "Faith Resilience: Everyday Experiences.” Societies 8, no. 1 (2018): 10.

Overland, Gwynyth. "Generating Theory, Biographical Accounts and Translation: A Study of Trauma and Resilience." International Journal of Social Research Methodology 14, no. 1 (2011): 61-75.

- Post Traumatic Survival: The Lessons of Cambodian Resilience. Phnom Penh: Cambridge Scholars Publishing, 2013.

Overland, Gwynyth Jones, and Virak Yenn. "Generosity and Resilience: Transnational Activity among the Khmer of Norway." Refuge: Canada's Journal on Refugees (2007): 129-34.

Purnell, L. Transcultural Health Care: A Culturally Competent Approach (4th Ed.). F. A. Davis, 2012.

Reimer,J. K. "A System Just for Children: Voices of Child Victims and Witnesses About Their Experiences in the Cambodian Criminal Justice System." Phnom Penh: Hagar International; UNICEF, 2015. 
Reimer, J. K., E. Langeler, Seng Sophea, and Sok Montha. "The Road Home: Toward a Model of "Reintegration" and Considerations for Alternative Care for Children Trafficked for Sexual Exploitation in Cambodia." Phnom Penh: Hagar International; World Vision Cambodia, 2007.

Schunert, T., S. Khann, S. Koa, C. Pot, L. B. Saupe, C. J. Lahar, and H. Nhong. "Cambodian Mental Health Survey Report." Department of Psychology, Royal University of Phnom Penh (2012).

Steiner, Jordan J., Jamie Kynn, Amanda M. Stylianou, and Judy L. Postmus. "Providing Services to Trafficking Survivors: Understanding Practices across the Globe." Journal of evidence-informed social work 15, no. 2 (2018): 151-69.

Tedeschi, Richard G., and Lawrence G. Calhoun. "The Posttraumatic Growth Inventory: Measuring the Positive Legacy of Trauma." Journal of traumatic stress 9, no. 3 (1996): 455-71.

Tillich, Paul. Dynamics of Faith. New York: HarperCollins, 1957.

Wright, Robert J. Research Methods for Counseling: An Introduction. SAGE Publications, 2014.

Wyatt, Zoe. "Dynamism: Reconceptualising Resilience in Recovery from Trauma." Asian Journal of Social Science Studies 6, no. 4 (2021): 29-34.

—_. "Pathways of Resilience and Recovery from Trauma for Cambodian Young People." Advances in Social Science and Culture 3 (2021): 80-98.

Yule, William, R. Stuvland, F. Baingana, and Patrick Smith. "Children in Armed Conflict." In Trauma Interventions in War and Peace, edited by B. L. Green, M. J. Friedman, J. T. de Jong, S. D. Solomon, T. M. Keane, J. A. Fairbank, B. Donelan and E. Frey-Walters, 217-42: Kluwer Academic/Plenum Publishers, 2003. 